\title{
INCREASING THE EFFICIENCY OF THE PYROLYSIS PROCESS
}

\author{
E. MAGARIL ${ }^{1,2} \&$ R. MAGARIL ${ }^{2}$ \\ ${ }^{1}$ Ural Federal University, Russia. \\ ${ }^{2}$ Tyumen Industrial University, Russia.
}

\begin{abstract}
Increasing the production volume of organic synthesis products demands improvements to the technology of the pyrolysis process to reduce costs and increase the yield of desired products, particularly ethylene, which is the dominant raw material in the petrochemical industry.

The aim of the present work is the substantiation of the methods that increase the pyrolysis selectivity for ethylene by influencing the stages of the radical chain process.

Based on the study of the relative reactivity of the various $\mathrm{C}-\mathrm{H}$ bonds in their interaction with the methyl radicals and with hydrogen atoms, which are the basic particles that determine the chain propagation in the pyrolysis, the possibility of increasing the process selectivity for ethylene was established, while simultaneously reducing the yield of the condensation products and suppressing the formation of pyrolytic carbon by replacing the methyl radical with hydrogen atoms, which was made possible by adding hydrogen to the feedstock in the amount of approximately $2 \%$ by weight.

It was found that allene lowers the activation energy of the thermal decomposition of hydrocarbons, thus increasing the depth of the reaction. Accelerating the rate of initiation of the radical chain process was observed at the temperatures below $1,000 \mathrm{~K}$. This opens up the possibility of increasing the efficiency of the pyrolysis process by recycling the propane fraction containing allene into the pyrolysis feedstock. This speeds up the process at low temperatures and suppresses the yield of the condensation products. Experimental data demonstrating the results of application of the proposed method are presented.
\end{abstract}

Keywords: allene, chain propagation stage, hydrogen, initiating stage, process selectivity, pyrolysis, yield of ethylene.

\section{INTRODUCTION}

The pyrolysis process has been under study for many years and is of interest at present [1-3]. For the production of ethylene, about 400 million tons of hydrocarbons such as the associated petroleum gas $\mathrm{C}_{2}-\mathrm{C}_{4}$ and liquid raw materials, mainly gasoline, are used per year. Currently, the world annual production of ethylene is about 140 million tons and is projected to increase up to 200 million by 2020 [4]. A significant part of the petrochemical production in the world is manufactured on the basis of ethylene and its nomenclature and production volume are continually expanding. The main industrial method to produce ethylene is by pyrolysis of the oil hydrocarbons. A continually growing demand for ethylene necessitates greater efficiency in the pyrolysis methods, which will permit greater selectivity for ethylene [3].

Pyrolysis occurs mainly through a radical chain mechanism and it is possible to govern the process by influencing the chain propagation stage or the chain initiating stage. Due to the limited data on the kinetics and mechanism of the reactions of different hydrocarbons as well as the lack of systematic study of the pyrolysis of complex hydrocarbon mixtures, these methods were not developed in the industrial pyrolysis and their substantiation is a highly topical task. 


\section{INFLUENCE OF HYDROGEN ON THE CHAIN PROPAGATION STAGE}

Chain propagation reactions during pyrolysis are caused mainly by three particles - a hydrogen atom $\dot{H}$, methyl $\dot{C} H_{3}$ and ethyl $\dot{C}_{2} H_{5}$ radicals. Composition of the primary products of the decomposition of hydrocarbon molecules depends on the structure of the radicals formed in the chain process. Taking into account the percentage ratio of methane, hydrogen and ethane yield 16:1.2:6 (wt.\%), received as a result of numerous laboratory investigations performed by the authors and industrial-scale plant data, and their molecular weights, the effect of the radicals $\dot{H}$, $\dot{C} H_{3}, \dot{C}_{2} H_{5}$, on the process shall relate as $\frac{1.2}{2}: \frac{16}{16}: \frac{6}{30}=0.6: 1.0: 0.2$ or $33: 56: 11(\%)$. Since the main influence on the chain propagation is caused by methyl radicals and hydrogen atoms, in our consideration the role of ethyl radicals is not taken into account. To determine the differences in behavior of the methyl radicals and hydrogen atoms, the relative reactivity of $\mathrm{C}-\mathrm{H}$ bonds towards them was investigated.

In order to define the relative reactivity of the $\mathrm{C}-\mathrm{H}$ bonds in reactions with hydrogen the pyrolysis of the designated mixture of individual hydrocarbons was carried out by means of the simulation laboratory apparatus under high dilution by hydrogen (the composition of the feedstock and products were determined chromatographically). In such conditions the methyl radical reacts with hydrogen by reaction (1) [5]:

$$
\dot{\mathrm{C}} \mathrm{H}_{3}+\mathrm{H}_{2} \rightarrow \mathrm{CH}_{4}+\dot{\mathrm{H}}
$$

with the rate much greater than that for the reaction with hydrocarbons (2):

$$
\dot{\mathrm{C}} \mathrm{H}_{3}+\mathrm{RH} \rightarrow \mathrm{CH}_{4}+\dot{\mathrm{R}}
$$

as the rate constant for the reaction (1) is more an order of magnitude than that for reaction (2) [6]. Thus, the substitution reaction occurs only due to hydrogen atoms by the first-order hydrocarbon reaction (3):

$$
\dot{H}+R H \rightarrow H_{2}+\dot{R}
$$

The data on the depth of decomposition ( $y$ ) of the individual hydrocarbons makes it possible to receive the values $k \tau$ upon the known equation describing the first-order reaction kinetics [7]:

$$
\lg (1-y)=k \tau
$$

where $k$ is the decomposition rate constant, $\tau$ is the time equal for all the components of the hydrocarbon mixture. From the ratio of the depth of decomposition of the individual hydrocarbons the relative reactivities of various $\mathrm{C}-\mathrm{H}$ bonds were calculated by the authors. For example, in the pyrolysis of the mixture containing propane and butane, based on the number of $\mathrm{C}-\mathrm{H}$ bonds of various types the ratio of the decomposition rate constants is equal to:

$$
\frac{k_{C_{4} H_{10}}}{k_{C_{3} H_{8}}}=\frac{6 \cdot 1+4 x}{6 \cdot 1+2 x}
$$

where the relative reactivity of the $\mathrm{C}-\mathrm{H}$ bond in the methyl group is equal to unity and $x$ is the relative reactivity of the $\mathrm{C}-\mathrm{H}$ bond in the methylene group. Thus, the relative reactivity of the $\mathrm{C}-\mathrm{H}$ bond in the methylene group can be calculated. Similarly the relative reactivities of the other $\mathrm{C}-\mathrm{H}$ bonds were found. The experimental results obtained by the authors are presented in Table 1.

Data presented in Table 1 show that hydrogen atoms react similarly with the primary and secondary $\mathrm{C}-\mathrm{H}$ bonds while the tertiary bonds in isoalkanes possess a reactivity level that is 4 times higher. 
Table 1: Relative reactivity of $\mathrm{C}-\mathrm{H}$ bonds in interaction with hydrogen.

\begin{tabular}{lc}
\hline Bond Type & Relative Reactivity \\
\hline$R_{C H}-H$ & 1 \\
&
\end{tabular}

*accepted.

To determine the reactivity of the $\mathrm{C}-\mathrm{H}$ bonds in the substitution reactions with the methyl radical the pyrolysis was carried out in a helium flow with the addition of $60 \mathrm{~mol} \%$ of propylene. Hydrogen atom reacts with propylene as follows [5]:

$$
\begin{gathered}
\dot{H}+C_{3} H_{6} \rightarrow n-C_{3} H_{7} \rightarrow C_{2} H_{4}+\mathrm{CH}_{3} \\
\dot{H}+C_{3} H_{6} \rightarrow H_{2}+\dot{C}_{3} H_{5}
\end{gathered}
$$

As a result the hydrogen atoms are substituted by methyl and allyl radicals. As the substitution reactions for the allyl radicals $\dot{C}_{3} H_{5}$ are much slower than those for the methyl radicals $\dot{\mathrm{C}} \mathrm{H}_{3}$ (the dissociation energy of the $\mathrm{CH}_{3}-\mathrm{H}$ bond is $75 \mathrm{~kJ} / \mathrm{mol}$ more than that of the $\mathrm{C}_{3} \mathrm{H}_{5}-\mathrm{H}$ bond by the data presented in [8]) they can be neglected.

From the experimental results obtained by the authors the relative reactivities of the various bonds in reactions with methyl radicals were evaluated in the same way as for hydrogen atoms, taking the reactivity of the primary $\mathrm{C}-\mathrm{H}$ bond to be equal to unity. The relative reactivities of the $\mathrm{C}-\mathrm{H}$ bonds in the substitution reactions with methyl radicals are shown in Table 2.

Comparison of the data presented in Tables 1 and 2 reveals that the hydrogen atoms are virtually nonselective in the reactions with primary and secondary bonds, while the methyl radicals show high selectivity. For example, the $\mathrm{H}$ atom in the n-pentane is equally likely to react with all the bonds and the probability of the primary decomposition with the ethylene formation, equal to the ratio of the primary $\mathrm{C}-\mathrm{H}$ bonds to the total number of $\mathrm{C}-\mathrm{H}$ bonds in the molecule is equal to $\frac{6}{12}$, i.e. in total $50 \%$. In reactions of the methyl radical with n-pentane with unequal reactivity of different $\mathrm{C}-\mathrm{H}$ bonds in interaction with $\dot{\mathrm{C}} \mathrm{H}_{3}$ the probability of the 
Table 2: Relative reactivity of $\mathrm{C}-\mathrm{H}$ bonds in interaction with methyl radical.

\begin{tabular}{lc}
\hline Bond Type & Relative Reactivity \\
\hline $\mathrm{RCH}_{2}-\mathrm{H}$ & 4.5 \\
& \\
&
\end{tabular}

*accepted.

primary bonds' formation is equal to $\frac{6 \cdot 1}{6 \cdot 1+4 \cdot 4.5+2 \cdot 7}$, i.e. in total $16 \%$. From a comparison of these results it is seen that processing the pyrolysis when the methyl radicals are substituted by hydrogen atoms, significantly improves the selectivity of the process for ethylene.

In Ref. [9] it was shown that replacing the methyl radicals with the hydrogen atoms is carried out by supplying hydrogen in the amount of approximately $2 \%$ by weight of the raw materials. To produce ethylene it is consumed in a significant concentration in reactions (8) and (8a):

$$
\begin{gathered}
\dot{R}+\mathrm{C}_{2} \mathrm{H}_{4} \rightarrow \dot{\mathrm{C}}_{2} \mathrm{H}_{3}+\mathrm{RH} \\
\dot{\mathrm{C}}_{2} \mathrm{H}_{3}+\mathrm{C}_{2} \mathrm{H}_{4} \rightarrow \mathrm{C}_{2} \mathrm{H}_{7} \rightarrow \mathrm{C}_{4} \mathrm{H}_{6} \\
\text { condensation products }
\end{gathered}
$$

The rate constant of the reaction (9) of vinyl radical with hydrogen

$$
\dot{C}_{2} H_{3}+H_{2} \rightarrow C_{2} H_{4}+\dot{H}
$$

is by about one order of magnitude greater compared with the rate constant of its reaction with ethylene [6]. Therefore, during the formation of $28 \mathrm{wt} . \%$ of ethylene in a mixture with 2 wt.\% of hydrogen the mole ratio of their concentrations is $1: 1$, herewith condensation of ethylene is suppressed and there is no reduction in its output. The effect of hydrogen on the results of the pyrolysis of fraction $85^{\circ} \mathrm{C}-150^{\circ} \mathrm{C}$ experimentally obtained by the authors is shown in Fig. 1. 


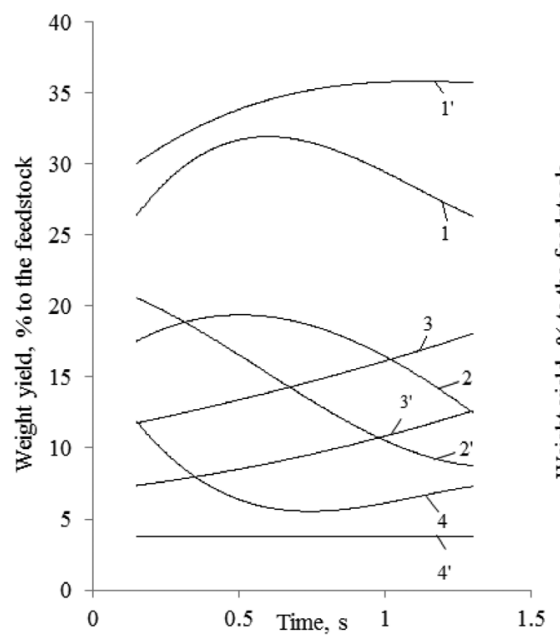

a)

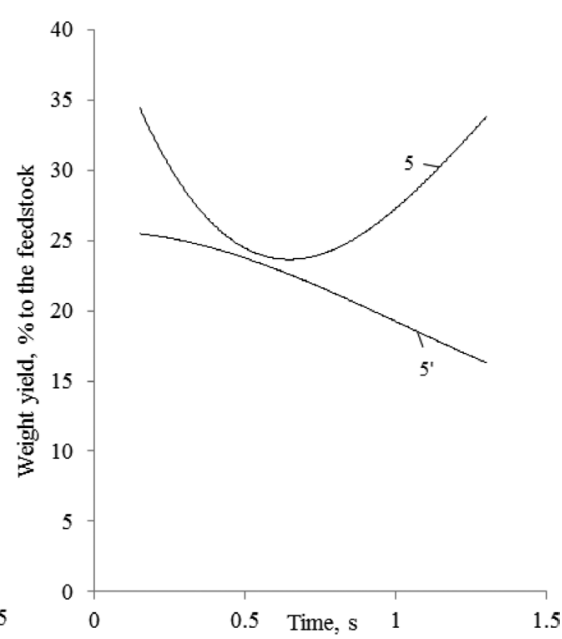

b)

Figure 1: Effect of hydrogen on the results of the pyrolysis of fraction $85^{\circ} \mathrm{C}-150^{\circ} \mathrm{C}$ ( $\mathrm{T}=810^{\circ} \mathrm{C}$, the total pressure is equal to atmospheric): (a) gaseous products; (b) liquid products; 1 - ethylene; 2 - propylene; 3 - methane; 4 - butadiene; 5 - $\mathrm{C}_{5}$ + liquid products, without hydrogen. $1^{\prime}-5$ ' - the same products with the introduction of 2 wt. $\%$ of hydrogen.

Replacement of the methyl radicals by the hydrogen atoms leads to some acceleration of the process, as reaction (1) is faster than reaction (2), while reaction (3) is much faster than reaction (2). The high partial pressures of hydrogen in the mixture under pyrolysis reduce extraction of the pyrolytic carbon on the walls of the reaction coil [10].

\section{INFLUENCE OF ALLENE ON THE CHAIN INITIATION STAGE}

The rate of the chain reaction $W$ in a steady state is described by the eqn $(10)[7,10]$ :

$$
W=k_{1} \cdot[\dot{R}] \cdot[M]
$$

where $k_{l}$ is the rate constant of the chain propagation, $\dot{R}$ is the chain carrier radical, $M$ is molecule of the raw material.

Concentration of the chain carrier radicals in a steady state is defined from the equality of the rates of the chain initiation and chain termination.

$$
v=k_{2} \cdot[\dot{R}]^{2}
$$

where $v$ is the rate of the chain initiation, $k_{2}$ is the rate constant of the radical

recombination.
By substituting the expression for $[\dot{R}]$, derived for the eqn $(11)\left([R]=\sqrt{\frac{v}{k_{2}}}\right)$ into the formula
(10), one can receive: (10), one can receive:

$$
W=k_{1} \cdot \sqrt{\frac{v}{k_{2}}} \cdot[M]
$$

Therefore, the chain reaction rate is proportional to the initiation rate to the power $\frac{1}{2}$. 
At the initial steps of the pyrolysis of alkanes the chain initiation occurs when breaking $\mathrm{C}-\mathrm{C}$ bonds. The formation of olefins containing $\mathrm{C}-\mathrm{C}$ bond, weakened by conjugation with a double bond about by $55 \mathrm{~kJ}[5,8]$, appears even at a shallow depth of decomposition. It was found by the authors that the thermal decomposition of hydrocarbons is greatly accelerated by introduction of allene (propadiene). The results of the experiments performed by authors on the effect of allen on thermal decomposition of hydrocarbons are presented in Table 3. Pyrolysis was carried out in quartz tubular reactors, placed in a tube furnace, with changing the reaction time and temperature.

Decrease in the activation energy with the addition of allene influences the reaction depth of the thermal decomposition of hydrocarbons. The authors' results of determining the activation energy are listed in Table 4.

Evaluation of the reaction rate constant (13):

$$
\mathrm{C}_{3} \mathrm{H}_{4}+\mathrm{C}_{3} \mathrm{H}_{8} \rightarrow \dot{\mathrm{C}}_{3} \mathrm{H}_{5}+\dot{\mathrm{C}}_{3} \mathrm{H}_{7}
$$

gives the value of approximately $10^{-11} \cdot e^{-\frac{181780}{R T}} \frac{\mathrm{cm}^{3}}{\text { molecule } \cdot \mathrm{s}}$, for the reaction (14)

$$
\mathrm{C}_{3} \mathrm{H}_{4}+\mathrm{C}_{3} \mathrm{H}_{6} \rightarrow 2 \dot{C}_{3} \mathrm{H}_{5}
$$

the rate constant is $10^{-11} \cdot e^{-\frac{113000}{R T}} \frac{\mathrm{cm}^{3}}{\text { molecule } \cdot \mathrm{s}}[11]$.

Table 3: Influence of allene on the depth of the thermal decomposition of the hydrocarbons.

\begin{tabular}{lccc}
\hline \multirow{2}{*}{$\begin{array}{l}\text { Allene addition, mol\% } \\
\text { to hydrocarbon }\end{array}$} & \multicolumn{2}{c}{ Reaction conditions } & $\begin{array}{c}\text { Depth of hydrocarbon } \\
\text { decomposition, } \%\end{array}$ \\
\cline { 2 - 3 } n-hexene-1 & Temperature, K & Time, s & \\
0 & 823 & 2.00 & 6.5 \\
0.5 & 823 & 2.00 & 20.1 \\
0 & 923 & 0.10 & 11.0 \\
0.5 & 923 & 0.10 & 21.4 \\
n-hexane & & & \\
0 & 923 & 0.06 & 5.2 \\
0.5 & 923 & 0.06 & 56.2 \\
0 & 963 & 0.02 & 4.5 \\
0.5 & 963 & 0.02 & 46.5 \\
cyclohexane & & & \\
0 & 933 & 3.90 & 20.5 \\
0.5 & 893 & 0.55 & 20.5 \\
0 & 973 & 0.19 & 7.0 \\
0.5 & 973 & 0.19 & 53.5 \\
\hline
\end{tabular}




\begin{tabular}{lccc}
\hline $\begin{array}{l}\text { Allene addition, mol\% } \\
\text { to hydrocarbon }\end{array}$ & Reaction conditions & $\begin{array}{l}\text { Depth of hydrocarbon } \\
\text { decomposition, } \%\end{array}$ \\
\cline { 2 - 3 } tetralin & Temperature, $\mathrm{K}$ & Time, $\mathrm{s}$ & \\
0 & 903 & 0.38 & 9.0 \\
1.5 & 903 & 0.38 & 45.0 \\
0 & 953 & 0.09 & 9.5 \\
1.5 & 953 & 0.09 & 55.6 \\
decalin & & & \\
0 & 923 & 0.26 & 20.5 \\
1.5 & 898 & 0.16 & 20.5 \\
0 & 973 & 0.04 & 2.3 \\
1.5 & 973 & 0.04 & 30.0 \\
\hline
\end{tabular}

Table 4: Activation energy of thermal decomposition of hydrocarbons in pure form and in the presence of allene.

\begin{tabular}{lccc}
\hline Hydrocarbon & $\begin{array}{c}\text { Activation Energy in a } \\
\text { Pure form, kJ/mol }\end{array}$ & $\begin{array}{c}\text { Allene Addition, } \\
\text { mol\% to Hydrocarbon }\end{array}$ & $\begin{array}{c}\text { Activation Energy with } \\
\text { Allene Addition, } \\
\mathrm{kJ} / \mathrm{mol}\end{array}$ \\
\hline n-hexene-1 & $244 \pm 7$ & 0.5 & $163 \pm 7$ \\
n-hexane & $258 \pm 10$ & 0.5 & $154 \pm 13$ \\
cyclohexane & $224 \pm 6$ & 0.5 & $130 \pm 10$ \\
tetralin & $215 \pm 16.5$ & 1.5 & $163 \pm 9$ \\
decalin & $151 \pm 10$ & 1.5 & $92 \pm 8$ \\
\hline
\end{tabular}

Table 5: Evaluation of changes in the rate of initiation of the thermal decomposition of hydrocarbons caused by introduction of allene.

\begin{tabular}{lcccccc}
\hline & \multicolumn{2}{c}{ Reaction Rates, molecule $\cdot \mathrm{cm}^{-3} \cdot \mathrm{s}^{-1}$} & \multicolumn{3}{c}{ Relative Rates } \\
\cline { 2 - 7 } $\mathrm{T}, \mathrm{K}$ & $\begin{array}{c}\text { Reaction } \\
(15)\end{array}$ & $\begin{array}{c}\text { Reaction } \\
(13)\end{array}$ & $\begin{array}{c}\text { Reaction } \\
(14)\end{array}$ & $\begin{array}{c}\text { Reaction } \\
(15)\end{array}$ & $\begin{array}{c}\text { Reaction } \\
(13)\end{array}$ & $\begin{array}{c}\text { Reaction } \\
(14)\end{array}$ \\
\hline 833 & $10^{11.775}$ & $10^{13.587}$ & $10^{14.906}$ & $1^{*}$ & 65 & 1,350 \\
900 & $10^{13.459}$ & $10^{14.452}$ & $10^{15.443}$ & $1^{*}$ & 10 & 95 \\
1,000 & $10^{15.479}$ & $10^{15.489}$ & $10^{16.088}$ & $1^{*}$ & 1.0 & 1.2 \\
1,053 & $10^{16.405}$ & $10^{15.965}$ & $10^{16.384}$ & $1 *$ & 0.4 & 1.0 \\
\hline
\end{tabular}

*accepted.

In Table 5 the comparison of the initiation rate is presented by the authors without allene by the reaction of monomolecular decomposition of propane [5] (15):

$$
\mathrm{C}_{3} \mathrm{H}_{8} \rightarrow \dot{\mathrm{C}}_{2} \mathrm{H}_{5}+\dot{\mathrm{C}} \mathrm{H}_{3}
$$

and with addition of 1 mol.\% of allene by the reactions (13) and (14). 
From the results of authors' calculation it is seen that allene accelerates the stage of initiation at a temperature below $1,000 \mathrm{~K}$. In the pyrolysis, allene is formed at temperatures above $1,000 \mathrm{~K}$ as a result of the highly endothermic decomposition reaction [5] (16):

$$
\dot{C}_{3} H_{5} \rightarrow C_{3} H_{4}+\dot{H}
$$

and has no effect on the propagation rate at these temperatures. During the process of rectification allene is extracted as a part of the propane fraction and its recycling into a feedstock material increases the rate of pyrolysis at low temperatures, increasing the yield of ethylene.

Furthermore, the formation of heavy products of condensation decreases and it is probably they are formed by a molecular mechanism. Table 6 presents the data, obtained by the authors, on the influence of allene on the yield of ethylene and the formation of condensation products during pyrolysis.

Table 7 presents the yields of the main products of the $n$-hexane pyrolysis at $800{ }^{\circ} \mathrm{C}$, which are the experimental results, derived by the authors.

The data obtained show that the pyrolysis temperature at a given time can be reduced by means of allene introduction.

The industrial testing was carried out by the authors on the pyrolysis installation of small power (60,000 tons of ethylene per year) located in Omsk, Russia. The testing was performed in a non-optimal mode. Outlet temperature of the pyrolysis furnace was $800{ }^{\circ} \mathrm{C}$, the time of process was $1 \mathrm{~s}$. Instead of hydrogen, a methane-hydrogen fraction with hydrogen content of $80 \mathrm{~mol} . \%$ was used. When supplying the methane-hydrogen fraction in amount of $2 \mathrm{wt} . \%$ per raw material with allene addition of $0.5 \mathrm{wt} . \%$ by raw material the ethylene output increased by 21.2 rel.\%.

Table 6: Influence of allene on the results of the pyrolysis of the fraction $70^{\circ} \mathrm{C}-100^{\circ} \mathrm{C}$ of the gasoline-raffinate at $820^{\circ} \mathrm{C}, 0.1 \mathrm{MPa}$, time of the process is $1 \mathrm{~s}$, volume ratio of the feedstock and inert diluent (helium) is $1: 3.66 \mathrm{~mol} / \mathrm{mol}$.

\begin{tabular}{lcc}
\hline \multirow{2}{*}{$\begin{array}{c}\text { Allene Addition wt.\% to } \\
\text { the Feedstock }\end{array}$} & \multicolumn{2}{c}{ Yield, wt.\% to the Feedstock } \\
\cline { 2 - 3 } & $\mathrm{C}_{2} \mathrm{H}_{4}$ & $\mathrm{C}_{5+}$ \\
\hline 0.0 & $24.7 \pm 0.7$ & $22.3 \pm 0.6$ \\
0.3 & $27.3 \pm 0.2$ & $19.1 \pm 0.6$ \\
0.5 & $27.8 \pm 0.3$ & $17.3 \pm 0.5$ \\
\hline
\end{tabular}

Table 7: Yields of the main products of the n-hexane pyrolysis at $800^{\circ} \mathrm{C}$ with the volume ratio of the feedstock and inert diluent (helium) equal to $1: 3.66 \mathrm{~mol} / \mathrm{mol}$.

\begin{tabular}{ccccc}
\hline \multirow{2}{*}{$\begin{array}{l}\text { Allene addition wt.\% } \\
\text { to the feedstock }\end{array}$} & Time of the pyrolysis, $\mathrm{s}$ & \multicolumn{3}{c}{ Yield, wt.\% } \\
\cline { 3 - 5 } & & $\mathrm{C}_{2} \mathrm{H}_{4}$ & $\mathrm{C}_{3} \mathrm{H}_{6}$ & $\mathrm{C}_{4} \mathrm{H}_{6}$ \\
\hline 0 & 0.5 & 33.0 & 17.3 & 5.0 \\
0.3 & 0.09 & 35.5 & 18.4 & 6.5 \\
\hline
\end{tabular}




\section{CONCLUSIONS}

The significance of ethylene as a priority raw material for the petrochemical industry points, suggests the importance of increasing the efficiency of the petroleum hydrocarbon's pyrolysis process, which is the main industrial method for producing ethylene. Theoretical substantiation of the methods to improve the pyrolysis process, increasing the selectivity of ethylene using the effect of hydrogen on the chain propagation stage and allene on the chain initiation stage was presented.

On the basis of the research carried out regarding the relative reactivity of different types of $\mathrm{C}-\mathrm{H}$ bonds with methyl radicals and hydrogen atoms, the authors demonstrated that hydrogen atoms are virtually not-selective in reactions with primary and secondary links, while methyl radicals are highly selective. This allows the selectivity of the pyrolysis process to ethylene to be significantly increased by conducting the pyrolysis process under conditions where the methyl radicals are substituted by hydrogen atoms.

In addition, the authors have found that the thermal decomposition of hydrocarbons at temperatures below $1,000 \mathrm{~K}$ is greatly accelerated by the addition of allene which lowers the activation energy for the thermal decomposition thus reducing the formation of heavy condensation products.

The results of investigations carried out by the authors revealed that the efficiency of the pyrolysis can be substantially improved by introduction into the feedstock in amount approximately $2 \mathrm{wt} . \%$ the recycle hydrogen, produced from the pyrolysis gas and recycling the propane fraction released from the pyrolysis gas, which contains allene produced during the pyrolysis.

\section{ACKNOWLEDGEMENT}

This research was supported by Act 211 Government of the Russian Federation, contract No 02.A03.21.0006.

\section{REFERENCES}

[1] Lewandowski, W.M., Radziemska, E., Ryms, M. \& Ostrowski, P., Modern methods of thermochemical biomass conversion into gas, liquid and solid fuels. Ecological Chemistry and Engineering, 18(1), pp. 39-47, 2011.

[2] Grigiante, M., Ischia, M., Baratieri, M., Maschio, R.D. \& Ragazzi, M., Pyrolysis analysis and solid residue stabilization of polymers, waste tyres, spruce sawdust and sewage sludge. Waste and Biomass Valorization, 1(4), pp. 381-393, 2010. http://dx.doi.org/10.1007/s12649-010-9038-2

[3] Wang, X.Q., Xie, C.G., Li, Z.T. \& Zhu, G.Q. Catalytic processes for light olefin production (Chapter 5). Practical Advances in Petroleum Processing, eds. C.S. Hsu \& P.R. Robinson, Springer Science - Business Media, Inc.: New York, Vol. 1, pp. 149-168, 2006.

[4] Global Ethylene Market Outlook: Low Cost Feedstocks Fuel The Next Wave Of Investments In North America and China. Inaugural Ethylene Forum Online www.media. corporate-ir.net/media_files/IROL/11/110877/05_Global_Ethylene_Market_Outlook_ Eramo.pdf

[5] Korzun, N.V. \& Magaril, R.Z., Thermal Processes of Refining, [in Russian], KDU: Moscow, pp. 10-20, 2008.

[6] Kondratiev, V.N., Rate Constants of Gas Phase Reactions, National Bureau of Standards: Washington, 1972. 
[7] Emanuel, N.M. \& Knorre, D.G., Chemical Kinetics; Homogeneous Reactions, Wiley: New York, 1973.

[8] Vedeneyev, V.I., Gurvich, L.V., Kondratyev, V.N., Medvedev, V.A. \& Frankevich Ye. L., Bond Energies, Ionization Potentials, and Electron Affinities, St. Martin's Press, Inc.: New York, 1966.

[9] Magaril, E. \& Magaril R, Increasing the selectivity of the hydrocarbon feedstock pyrolysis. WIT Transactions on Ecology and the Environment, 186, pp. 529-534, 2014. http://dx.doi.org/10.2495/ESUS140461

[10] Magaril, R.Z., Theoretical foundation of the chemical processes of oil refining, [in Russian], KDU: Moscow, p. 69, 2010.

[11] Klementyev, A., Magaril, R., Korzun, N. \& Magaril, E., Efficiency improvement of pyrolysis. WIT Transactions on Ecology and the Environment, 190(2), pp. 861-865, 2014. http://dx.doi.org/10.2495/EQ140802 